\title{
Bowel Obstruction due to Sciatic Hernia
}

\author{
Masanori Tokunaga ${ }^{a}$ Ken Shirabe $^{b}$ Nami Yamashitab Naoki Hiki ${ }^{a}$ \\ Toshiharu Yamaguchia \\ ${ }^{a}$ Department of Gastroenterological Surgery, Cancer Institute Hospital, Japanese Foundation for Cancer Research,

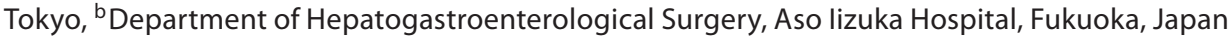

A 72-year-old woman showed massive ascites and sciatic hernia, which was composed solely of ascites, on computed tomography (CT) done in February 2005 as part of a regular follow-up for liver cirrhosis at Aso Iizuka Hospital. Surgical intervention was not chosen as there was no sign of visceral herniation (fig. 1). This patient subsequently presented with abdominal distension in May 2005. CT revealed small bowel obstruction due to

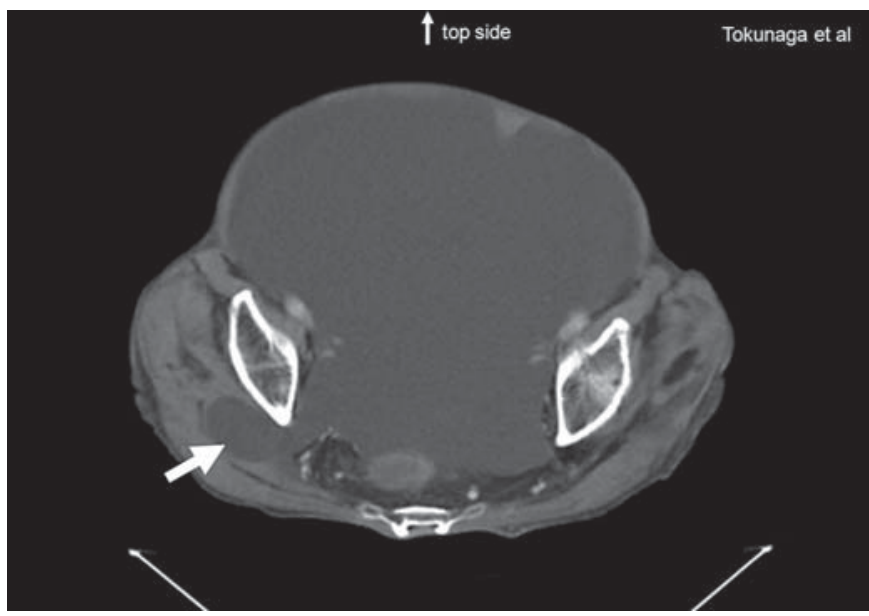

Fig. 1. An abdominal CT done 3 months before revealed rightside sciatic hernia. The hernia sac contained only ascites and the patient was asymptomatic at that time (white arrow). incarcerated sciatic hernia, and she underwent emergency operation (fig. 2). The operation was performed using the transgluteal approach (fig. 3). The sciatic hernia was repaired by suturing the piriformis muscle and the gluteus maximus muscle, without bowel resection because there was no evidence of ischemic change. She was discharged on the 14th postoperative day without any trouble.

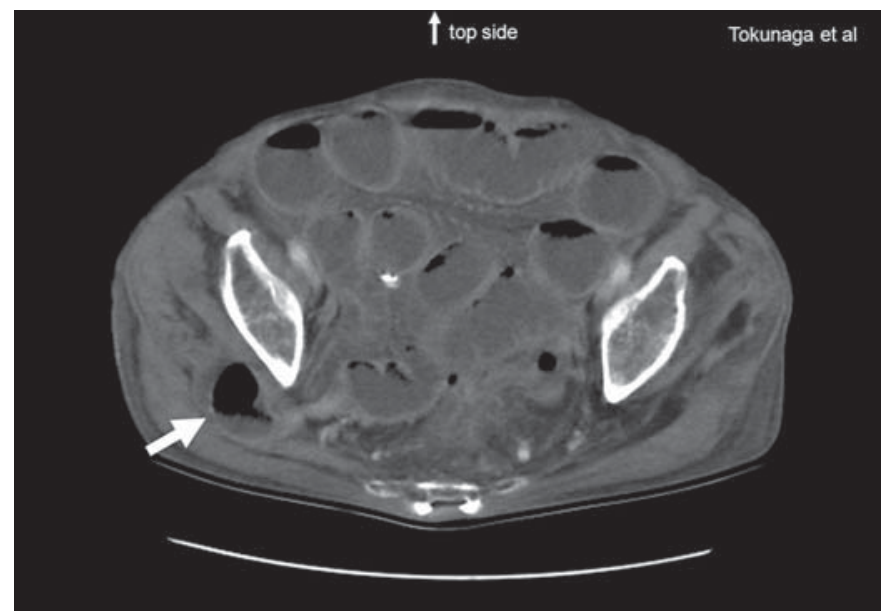

Fig. 2. An enhanced abdominal CT indicated small bowel obstruction due to incarcerated sciatic hernia (white arrow). The small intestinal wall was fully enhanced, indicating that there was no ischemia.

\section{KARGER}

Fax +41613061234 E-Mail karger@karger.ch www.karger.com
(C) 2008 S. Karger AG, Basel

0253-4886/08/0253-0185\$24.50/0

Accessible online at:

www.karger.com/dsu
Masanori Tokunaga, MD

Department of Gastroenterological Surgery, Cancer Institute Hospital

Japanese Foundation for Cancer Research

3-10-6 Ariake, Koto-ku, Tokyo 135-8550 (Japan)

Tel. +81 33520 0111, Fax +81 33520 0141, E-Mail masanori.tokunaga@jfcr.or.jp 


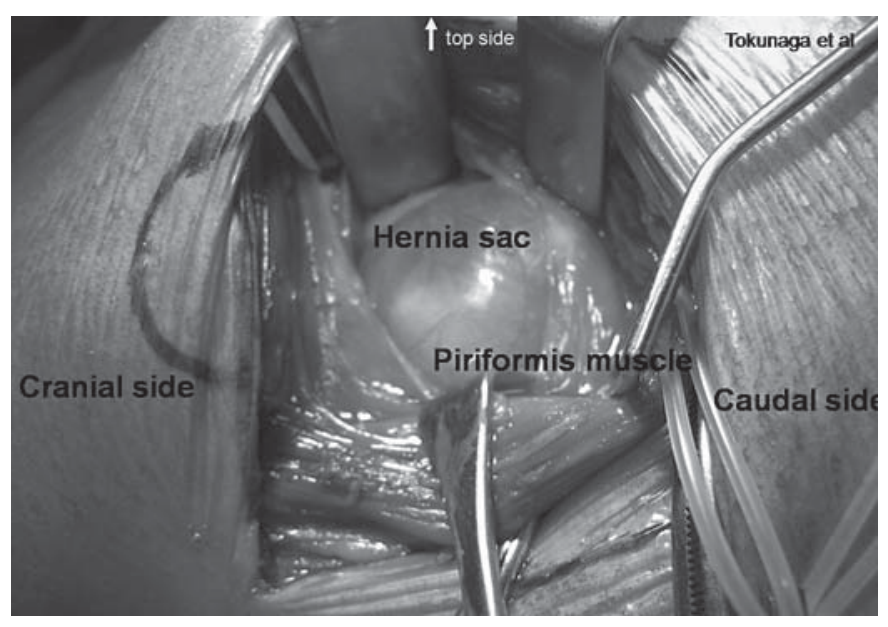

Fig. 3. The operation was performed using a transgluteal approach. The hernia sac protruded through the suprapiriformis area.

Sciatic hernia is extremely rare and it remains unclear whether it is congenital or acquired $[1,2]$. In the present case, increased intra-abdominal pressure due to massive ascites may have been the cause of sciatic hernia, and thus the case was considered as acquired sciatic hernia. We have shown that the transgluteal approach is feasible for sciatic hernia because it enables complete repair of the hernia without major surgical stress if visceral organs show no ischemic changes $[2,3]$.

References atr Surg 1992;27:1603-1604

2 Gaffney LB, Schanno JF: Sciatic hernia; a case of congenital occurrence. Am J Surg 1958;95:974-975

3 Ghahremani GG, Michael AS: Sciatic hernia with incarcerated ileum: CT and radiographic diagnosis 1991;16:120-122. 